\title{
Medical emergencies on large passenger ships without doctors: the Oslo-Kiel-Oslo ferry experience
}

\author{
Thor-Erik Holt ${ }^{1}$, Agnar Tveten ${ }^{2}$, Eilif Dahl ${ }^{2}$ \\ ${ }^{1}$ Color Line, Oslo, Norway \\ ${ }^{2}$ Department of Occupational Medicine, Norwegian Centre for Maritime and Diving Medicine, \\ Haukeland University Hospital, Bergen, Norway
}

\begin{abstract}
Background: The Oslo-Kiel-Oslo route is currently the only direct ferry crossing between Norway and Germany, covered by 2 cruise-and-cars ferries carrying about 2,600 passengers each and sailing every day (20 h at sea, $4 \mathrm{~h}$ in port). Unlike most ocean going cruise vessels, they are not required to carry a physician but an on-board paramedic handles medical emergencies. The aim of the study was to provide data on medical emergencies leading to helicopter evacuations (helivacs) or other urgent transfers to facilities ashore from the two ferries during a 3-year period.

Materials and methods: Data about the ferries, passengers, crew, helivacs and other medical transfers were collected from official company statistics and the paramedics' transfer reports.

Results: A total of 169 persons, including 14 (8.3\%) crewmembers, were transferred from the ferries to land-based facilities by ambulance while alongside $(n=80 ; 47.3 \%)$ or evacuated by helicopter $(n=85$; $50.3 \%)$ and rescue boat $(n=4 ; 2.4 \%)$ during the 3-year period. Transfer destinations were Denmark $(n=53)$, Germany $(n=49)$, Norway $(n=48)$ and Sweden $(n=19)$. The passenger helivac rate was 2.4 per 100,000 passenger-days. One person was airlifted from a ferry every 2 weeks. Among helivacs, $40 \%$ were heart-related, and more cardiac cases were airlifted than transferred by ambulance in port.

Conclusions: All helivac requests were made after discussion between the ferry's paramedic and telemedical doctors ashore and agreement that the medical challenge exceeded the ferry's capability. This close cooperation kept the threshold for arranging helivacs from the ferries low, enabling short transport times to land-based facilities for critically ill patients. Further studies, including feedback from the receiving hospitals, are needed to determine measures that can reduce possible helicopter overutilisation without compromising patient safety and outcome.
\end{abstract}

(Int Marit Health 2017; 68, 3: 153-158)

Key words: cruise ferry, medical patient transfer, helicopter evacuation (helivac), paramedic, Tele-medical Maritime Assistance Service (TMAS), maritime medicine

\section{INTRODUCTION}

According to the Maritime Labour Convention 2006 [1], "ships carrying 100 or more persons and ordinarily engaged on international voyages of more than three days' duration shall carry a qualified medical doctor who is responsible for providing medical care". All other ships are required to have at least one seafarer on board competent to provide medical first aid [1].

Ferries are defined as boats or ships for conveying passengers and goods, especially over a relatively short distance and as a regular service [2]. The Oslo-Kiel-Oslo route is currently the only direct ferry crossing between Norway and Germany. One company covers it with two large ferries of more than 2,500 passengers each. Each scheduled sailing takes $20 \mathrm{~h}$, followed by a 4-h turnaround in port (Fig. 1). Because their voyages last less than 3 days, the Oslo-Kiel ferries - like most ferries around the world - do not carry ship's doctors, but due to a company decision both have a paramedic aboard.

Little is published about how medical emergencies are handled on passenger ships without ship's doctors. The 


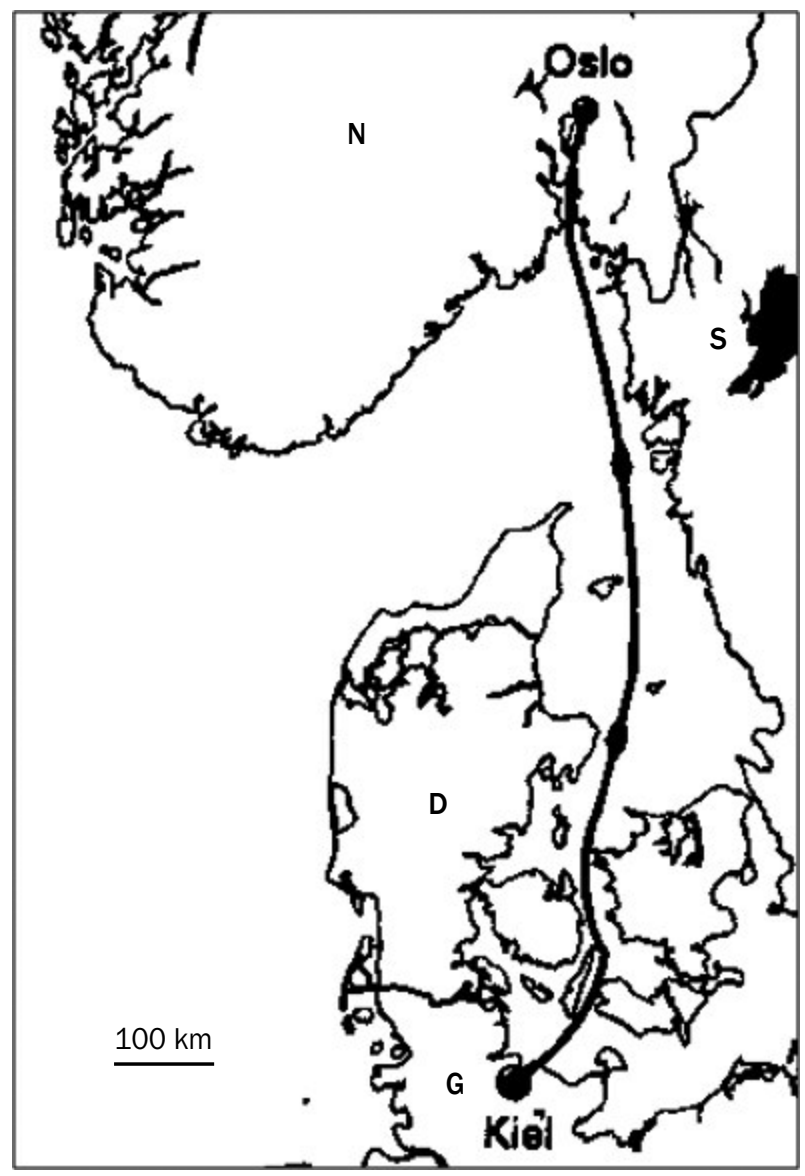

Figure 1. Map of Denmark(D)and of neighbour regions of Norway (N), Sweden (S), and Germany (G) showing the itineraries (Oslo-Kiel and Kiel-Oslo) of the two cruise-and-car ferries

present report aims to provide and discuss data on medical emergencies leading to helicopter evacuations (helivacs) or other urgent transfers to facilities ashore from the two ferries crossing between Norway and Germany during a 3-year period.

\section{MATERIALS AND METHODS}

\section{THE FERRIES}

The study comprises medical emergency data during a 3-year period from the two sister ships that currently cover the only direct ferry connection between Norway and Germany. They are large cruise-ferries with car decks holding 550-750 cars: Color Fantasy (built 2004) and Color Magic (built 2007); both 75,000 gross tonnage, registered in The Norwegian Ordinary Ship Register (NOR) and flying the Norwegian flag.

\section{PASSENGERS AND CREW}

Maximum number of passengers per ferry is approximately 2,600; mainly round-trip tourists Oslo-Kiel-Oslo or Kiel-Oslo-Kiel, tourists to Northern Scandinavia from the European continent and back, on-board conference participants and long-haul truck drivers. Most passengers are below 60 years of age, whilst about $25 \%$ are between 60 and 80 years of age. Crew compliment is about 285 officers, staff and crew per ferry, mostly Norwegians.

\section{ITINERARY}

The all-year itinerary is Oslo-Kiel and Kiel-Oslo non-stop (Fig. 1). The distance between Oslo and Kiel is 365 nautical miles, and during each voyage the ferry enter Norwegian, Swedish, Danish and German territorial waters. Service speed of the ferries is 20 knots and each voyage takes $20 \mathrm{~h}$, followed by $4 \mathrm{~h}$ in port. Every day one ferry departs from Oslo and one from Kiel at 14:00 $\mathrm{h}$ and arrives the next morning at 10:00 h.

\section{MEDICAL RESOURCES ON EACH FERRY}

- A separate infirmary is used exclusively for medical purposes. The infirmary has i.a. 1-2 ward beds, monitor/defibrillator with 12-lead electrocardiogram, blood pressure, pulse rate, temperature, EtCO2 and oxygen saturation monitoring capabilities, modest laboratory facilities (haemoglobin, urine sticks, C-reactive protein, blood sugar) and tele-medical communication systems.

- One paramedic (with 4 years of medical education) on 24/7 call and working 2 weeks on and 2 weeks off in rotation.

- The chief officer, who is in charge of medical emergencies aboard if no paramedics, has medical first aid training at ship master level.

- An infirmary team of 6 crewmembers with extra first aid training provided by the ferry's paramedic.

- All crewmembers have first aid training according to the International Convention on Standards of Training, Certification and Watch-keeping for Seafarers (STCW) [3], provided by approved maritime safety centres in Norway.

- Medical professionals among the passengers may be asked to volunteer during emergencies via the public announcement system.

- Landing area for helicopters (helipad) aft on deck 12, with access by wheelchair and stretcher from the infirmary. The helipad has a maximum weight capacity of 15 tons and a maximum rotor diameter of $23 \mathrm{~m}$. Most helivacs are done after landing the helicopter on the helipad, but at times weather conditions and technical problems make rescue hoisting necessary.

\section{CHAIN OF EMERGENCY COMMUNICATIONS}

The patient in need of medical attention calls the ship's paramedic through the ship's reception. The paramedic promptly evaluates the patient in the ship's infirmary. 
Table 1. Number of medical emergency transfers to land-based facilities from two cruise-and-car ferries Oslo-Kiel-Oslo during a 3-year period, according to mode of transportation

\begin{tabular}{llll}
\hline Means of evacuation & $\begin{array}{l}\text { No. (\%) of persons } \\
\text { transferred }\end{array}$ & $\begin{array}{l}\text { No. (\%) of passengers } \\
\text { transferred }\end{array}$ & $\begin{array}{l}\text { No. (\%) of crew } \\
\text { transferred }\end{array}$ \\
\hline Helicopter & $85(50.3 \%)$ & $76(49 \%)$ & $9(64.3 \%)$ \\
Rescue boat & $4(2.4 \%)$ & $4(2.6 \%)$ & $0(0 \%)$ \\
Ambulance while alongside & $80(47.3 \%)$ & $75(48.4 \%)$ & $5(35.7 \%)$ \\
Total & $169(100 \%)$ & $155(100 / 90.7 \%)$ & $14(100 / 8.3 \%)$
\end{tabular}

Minor or less serious conditions are dealt with on board and are referred to medical professionals in the next port if necessary.

If the paramedic is in doubt or considers the patient's condition to exceed his/her (i.e. the ferry's) capability, the chief officer is informed and the Norwegian Tele-medical Maritime Assistance Service (TMAS), Radio Medico Norway (RMN), in Bergen, Norway, is contacted for advice [4]. After review of the case the RMN physician on call determines, in discussion with the paramedic, whether or not medical disembarkation of the patient is indicated.

If shore-side medical assistance is deemed necessary, the Joint Rescue Coordination Centre (JRCC) Southern Norway, situated near Stavanger, Norway, is contacted directly by RMN. JRCC coordinates transfer of the patient with the most appropriate Search and Rescue (SAR) service of Norway, Sweden, Denmark or Germany [4]. During discussions between the RMN doctor ashore, the paramedic and the captain/chief officer a decision is made as to the most appropriate type of transfer in each case: helicopter evacuation (helivac), SAR rescue boat or ambulance while alongside: Patient $\rightarrow$ Paramedic $\rightarrow$ Radio Medico Norway $\rightarrow$ $J R C C$ Norway $\rightarrow$ SAR Norway/Sweden/Denmark/Germany $\rightarrow$ Hospital ashore.

\section{DATA REGISTRATION}

Data regarding the ferries, passengers and crew was gathered from official company statistics. Patient identifying data were not collected. The authors were given access to limited anonymous data from the paramedics' evacuation reports to their administrative superiors, the chief officers, for the 3-year (36-month or 156-week) period from 01 January 2014 to 31 December 2016. The paramedics decided on a provisional diagnosis prior to patient transfer and grouped the conditions into six categories they considered particularly time sensitive: heart-related, stroke-related, fracture-related, abdominal pain-related, respiratory-related and pregnancy-related. All other conditions were classified as: Other.

Collected data were: provisional diagnostic group presented by the paramedic to the RMN physician, passenger or crew status, and type of transfer from ferry to medical facility ashore (evacuation by helicopter or SAR boat; ambulance or taxi while alongside).

\section{FOR CALCULATIONS OF EVACUATION RATES AND FREQUENCIES}

- One passenger $=1$ passenger-day and one crewmember $=1 \mathrm{crew}$-day, since each voyage was 1 day $=24(20+4) \mathrm{h}$.

- Three years $=36$ months $=156$ weeks .

- Total number of crewmembers carried (= crew-days) aboard the two ferries during the 3 years $=$ average number of crew per ferry and voyage $\times$ number of ferries $\times$ number of days.

- Evacuation rate per 100,000 persons = number of persons evacuated by helicopter or rescue boat $\times 100,000$ per number of person-days.

\section{ETHICS AND STATISTICS}

The study was based on paramedic reports that were part of the company's quality improvement system and ethics committee approval was therefore not required [5]. Comparisons were done with the $\chi^{2}$ test and $p$-values less than 0.05 were considered statistically significant.

\section{RESULTS}

During the 3-year period, 169 persons (14 crew) were transferred for medical emergencies from the two ferries to medical facilities ashore in Norway, Sweden, Denmark and Germany: 85 persons ( 9 crew) were evacuated from the two ferries by helicopter and 4 passengers by rescue boat, and 80 persons ( $5 \mathrm{crew}$ ) were transferred by automobile while alongside (Table 1). While the average number of passenger days was about the same, the number of medical transfers tended to increase - from 42 in 2014 to 55 in 2015 and 72 in 2016. Transfers were done to medical facilities in Denmark $(n=53)$, Germany $(n=49)$, Norway $(n=48)$ and Sweden $(n=19)$.

An average of 56 persons ( 51 passengers +5 crew) were transferred from the two ferries to medical facilities ashore per year, i.e. 10 persons every 2 months - or 2.5 persons were medically transferred from each ferry every month. 
Table 2. Helicopter evacuations and other emergency transfers of 169 persons from two cruise-and-car ferries Oslo-Kiel-Oslo to land-based facilities during a 3-year period, according to the paramedics' provisional diagnoses

\begin{tabular}{llll}
\hline Tentative diagnosis & Helicopter evacuations (\%) & Other transfers (\%) & Total (\%) \\
\hline Heart-related & $34(40 \%)$ & $21(25 \%)$ & $55(38.5 \%)$ \\
Stroke-related & $8(9.4 \%)$ & $13(15.5 \%)$ & $21(12.4 \%)$ \\
Fracture-related & $8(9.4 \%)$ & $12(14.3 \%)$ & $20(11.8 \%)$ \\
Acute abdomen-related & $7(8.2 \%)$ & $9(10.7 \%)$ & $16(9.5 \%)$ \\
Respiratory-related & $6(7.1 \%)$ & $6(7.1 \%)$ & $12(7.1 \%)$ \\
Pregnancy-related & $5(5.9 \%)$ & $1(1.2 \%)$ & $6(3.6 \%)$ \\
Other & $17(20 \%)$ & $22(26.2 \%)$ & $39(23.1 \%)$ \\
Total & $85(100 \%)$ & $84(100 \%)$ & $169(100 \%)$
\end{tabular}

Boat rescues were few $(n=4)$. They were done either just after departure or when close to land (suspected stroke, acute abdominal pain, commotio cerebri and intoxication), and the time intervals between evacuation request and patient debarkation were short (20-50 min).

Half the passenger transfers and two thirds of the crew transfers were helicopter evacuations. An average of 28 persons ( 25 passengers $+3 \mathrm{crew}$ ) were airlifted by helicopter from the two ferries per year ( $=2$ helivacs every month); thus, there were one helivac from each ferry every month.

The two ferries had a total of 1.1 million passenger-days and 0.2 million crew-days a year, i.e. 3.9 million person-days during the 3-year period. Thus, the patient transfer rate from the ferries to shore-side medical facilities per 100,000 person-days was 4.3 (passenger rate: 4.7 ; crew rate 2.3 ), and the total evacuation rate (helicopter + rescue boat) per 100,000 person-days was 2.3 (passenger rate 2.4; crew rate 1.5). The passenger helivac rate per 100,000 passenger-days was 2.4 .

Table 2 shows the distribution of all the patients transferred to medical facilities ashore from the two ferries, as well as those evacuated by helicopter, according to diagnostic category.

Among helivacs, $40 \%$ were heart-related, and more cardiac cases were airlifted rather than transferred by automobile in port (34 vs. $21 ; p<0.05)$. Most pregnancy-related cases were airlifted ( 5 vs. 1 ), but the numbers are too small to show a significant difference (Table 2).

\section{DISCUSSION}

This paramedic-based registration study is the first report on medical emergencies and evacuations from large passenger ships without doctors. It shows how the paramedics handled urgent situations during a 3-year period on two large international cruise-and-car ferries that cross daily between Norway and Germany. Such data are not readily available from shipping companies, and these ferries were of particular interest for several reasons: they comprised the total direct ferry transport between Norway and Germany during the study period, they carried a large population of passengers and crew, the time at sea between the two ports was long ( $20 \mathrm{~h}$ ), and ship deviation was not possible due to a tight time schedule with short (4 h) turnaround in port. Furthermore, there were additional challenges regarding patient transfer logistics because the ferries passed through territorial waters of 4 different countries every trip and evacuations were arranged through rescue services of all 4 countries.

Primarily part of the shipping company's quality improvement programme, the present study has many limitations and weaknesses, but the data it offers may be useful for other ferries and for future studies because hardly any information has so far been available about this subject.

About half the medical transfers were by ambulance while the ferries were alongside, half were helivacs and very few $(n=4)$ were done by rescue boat. From each ferry 1 person was transferred to a medical facility ashore every week, of which 1 person was airlifted every 2 weeks.

In contrast to the ferries in the present series, some cruise studies from ships with a doctor aboard have reported more transfers of patients in port than airlifts:

In a study from 1991 looking at a total of 172 cruises originating in the United States, Peake et al. [6] reported 203 medical disembarkations before cruise completion in a population of $1,537,298$ passenger-days. The transfer rate per 100,000 passenger-days was 13.2 , which is higher than the ferries' corresponding rate of 4.7. But most of the cruise ships visited several ports per cruise, their mode of transfer was not specified, and helivacs were not mentioned. The cruise ships were smaller than the ferries and sailed with a mean of 1,143 passengers per cruise. Peake et al. [6] concluded that a ship's physician could expect to medically disembark four passengers per month before the cruise end. 
In a combined study of three world cruises of 90-106 days duration with about 600 passengers each, 18 passengers were hospitalised by ambulance when the ships reached their next or final ports [7-9]. The medical transfer rate per 100,000 passengers was lower than that of the ferries (1.8 vs. 4.7). Helivacs were possible by rescue hoisting but none were done during any of these three world cruises [7-9].

The most common cause for ferry helivacs were heart-related symptoms (40\%), which corresponds to a study of 397 helivacs of workers from 202 oilrigs off the United States Gulf Coast in 2002-2012 (cardiovascular diseases: $26-45 \%$ ) [10]. Similarly, 35\% of 104 critically ill patients airlifted to a Florida hospital from cruise ships in the Caribbean in 1999-2000 had heart conditions [11]. However, the mean overall delay between the initial call from the ship's physician and patient arrival at the receiving hospital was long (15.4 $\pm 11.7 \mathrm{~h}$ ), which is only about $4 \mathrm{~h}$ less than each entire ferry voyage in our study.

Speedy transfer of chest pain patients to modern land-based facilities may be crucial, and even more so for patients with suspected ischaemic stroke for which fibrinolytic therapy has been recommended for use within 3-4.5 h $[12,13]$. That time limit can in theory be met for most parts of the Oslo-Kiel-Oslo ferry itinerary but rarely for vessels cruising to remote areas of the world.

The decision to helivac from the ferries was in all cases taken after discussion between the ship's paramedic and management, the on-call Radio Medico physician, JRCC Norway and the contacted SAR unit. The fact that the paramedic found the medical challenge to exceed the ferry's capability, made all the helivacs appropriate. But reservations from just one of these parties may have led to the helivac not going ahead. This study did not look at how often and why helivac requests were declined or aborted.

The threshold for arranging helivacs from the ferries in our study appears to be lower than on cruise vessels with doctor(s), nurses and more elaborate medical facilities aboard. Reasons for this include a streamlined rescue operation process, good cooperation between the different parties in the four countries, high expectations of fast and safe transfer to superior medical care ashore from passengers and crew, limited monitoring possibilities aboard (only one paramedic to attend to all passengers and crew), adequate helicopter rescue resources in the vicinity, practical helipad facilities aboard, short distances from ferry to modern medical facilities ashore, extensive cost coverage by national and/or travel insurance, and busy and short (4 h) turnaround in the two ports.

If appropriately used, air rescue allows prompt transport to a hospital suitable for definitive treatment when minimisation of pre-hospital time is crucial $[13,14]$. Landing on a vessel's helipad is a complex aviation exercise and requires that the pilot is "deck-landing qualified" [15]. Helivacs from cruise ships are usually done by rescue hoisting even when the vessel has a helipad, often located on a forward deck. On the ferries the helipad is placed on an aft deck and in most incidences the helicopter could land. Landing is in many ways superior to rescue hoisting as it is more comfortable and less frightening for the patient, allows a shorter time on scene for the helicopter and more rapid loading of the patient. However, even under ideal conditions helivac is an expensive and limited resource with potential safety concerns and the risks must always be balanced against any potential benefit [15].

The costs of helivacs from ferries in Northern Europe are unknown. In the United States, helicopter emergency services have been shown to cost from 5 to 15 times the rate of ground transportation and there has been increasing pressure nationwide to limit helivac use to patients who are likely to benefit from air rather than ground transport [16].

Receiving patients airlifted from cruise vessels in the Caribbean, Prina et al. [11] found that the ship's doctors' diagnostic accuracy was $>90 \%$ and the decision to evacuate was highly appropriate; air evacuation was considered necessary in $96 \%$ of the patients. To determine the paramedics' accuracy, similar, prospective studies with feedback from the receivers are necessary.

By hiring paramedics instead of using a regular navigation officer to handle patients on their long-range ferries, the shipping company went above and beyond international regulations. For planning of future ferry staffing it will be helpful to know how busy the paramedics were with ferry patients who did not need transfers. This should be registered in upcoming ferry studies.

Can "unnecessary" helivacs be avoided if doctors or more medical personnel rather than only one paramedics work on the ferries or if more advanced medical equipment is installed? Videoconferences between the ferries and TMAS have been tried to improve communication but will it be of real value in daily practice? More elaborate studies are needed to answer such questions and also to determine to what extent the time saved by helivacs rather than ambulance transfers in the next port make a difference to patient outcome and safety. Feedback from the receiving hospitals was not available for the present study, but could provide further information about measures to reduce potential helicopter overutilisation.

The chief officers of the ferries were pleased with the paramedic arrangement since all maritime officers are usually too busy with non-medical chores to look after critically ill patients when evacuations or other transfers must be arranged. Navigation officers on smaller ferries doing shorter crossings are therefore also lobbying for adding paramedics, 
pointing out that passengers are now "spoiled" by conditions on ocean going cruise ships and now have high expectations regarding medical service aboard ferries.

\section{CONCLUSIONS}

In conclusion, all helivac requests were made after discussion between the ferry's paramedic and tele-medical doctors ashore, and agreement that the medical challenge exceeded the ferry's capability. This close cooperation kept the threshold for arranging helivacs from the ferries low, enabling short transport times to land-based facilities for critically ill patients. Further studies, including feed-back from the receiving hospitals, are needed to determine measures that can reduce possible helicopter overutilisation without compromising patient safety and outcome.

\section{POTENTIAL CONFLICT OF INTEREST}

Apart from their employment, the authors have no commercial, financial or other relationships related to the subject of this article.

\section{ORAL PRESENTATION}

Thor-Erik Holt, Master Mariner, presented data from this study at The Norwegian Sea Health Conference in Bergen, Norway, on 07-08 September 2016.

\section{REFERENCES}

(Internet references accessed 06 August 2017)

1. International Labour Organization. Maritime Labour Convention. http://www.ilo.org/wcmsp5/groups/public/@ed_norm/@normes/ documents/normativeinstrument/wcms_090250.pdf (2006).

2. Oxford English Dictionary. Oxford University Press, UK. https:// en.oxforddictionaries.com/definition/ferry (2017).

3. International Maritime Organization. International Convention on Standards of Training, Certification and Watchkeeping for Seafarers (STCW).http://www.imo.org/en/KnowledgeCentre/IMOAndTheUnitedNations/Pages/default.aspx.

4. Norwegian Centre for Maritime and Diving Medicine. Radio Medico. http:// www.ncmm.no/about-radio-medico-norway/contact-radio-medico.
5. NHS Health Research Authority. Defining research - guidance from the Research Ethics Service. http://www.hra.nhs.uk/documents/2016/06/defining-research.pdf.

6. Peake DE, Gray CL, Ludwig MR, et al. Descriptive epidemiology of injury and illness among cruise ship passengers. Ann Emerg Med. 1999; 33(1): 67-72, doi: 10.1016/s0196-0644(99)70419-1, indexed in Pubmed: 9867889.

7. Dahl E. General practice at sea [Almenpraksis til sjøs]. Tidsskr Nor Laegeforen. 1979; 99(6): 327-330.

8. Dahl E. Anatomy of a world cruise. J Travel Med. 1999; 6(3): 168-171, doi: 10.1111/j.1708-8305.1999.tb00855.x, indexed in Pubmed: 10467153.

9. Dahl E. Medical practice during a world cruise: a descriptive epidemiological study of injury and illness among passengers and crew. Int Marit Health. 2005; 56(1-4): 115-128, indexed in Pubmed: 16532590.

10. Thibodaux DP, Bourgeois RM, Loeppke RR, et al. Medical evacuations from oil rigs off the Gulf Coast of the United States from 2008 to 2012: reasons and cost implications. JOEM. 2014; 56(7): 681-685, doi: 10.1097/JOM.0000000000000221, indexed in Pubmed: 24988094.

11. Prina LD, Orzai UN, Weber RE. Evaluation of emergency air evacuation of critically ill patients from cruise ships. J Travel Med. 2001; 8(6): 285-292, doi: 10.2310/7060.2001.23971, indexed in Pubmed:11726292.

12. American Heart Association. Advanced cardiovascular life support. Provider manual 2016.

13. Reiner-Deitemyer V, Teuschl Y, Matz K, et al. Austrian Stroke Unit Registry Collaborators. Helicopter transport of stroke patients and its influence on thrombolysis rates: data from the Austrian Stroke Unit Registry. Stroke. 2011; 42(5): 1295-1300, doi: 10.1161/ STROKEAHA.110.604710, indexed in Pubmed: 21441156.

14. Schellhaaß A, Popp E. Luftrettung: Aktueller Stellenwert und praktische Aspekte [Air rescue: current significance and practical issues]. Anaesthesist. 2014; 63(12): 971-980, indexed in Pubmed: 25430664.

15. Williams S, Dahl E. Briefing notes on emergency medical disembarks by helicopter at sea in North America. Int Marit Health. 2014; 65(1): 7-12, doi:10.5603/MH.2014.0002, indexed in Pubmed: 24677120.

16. Hirshon JM, Galvagno SM, Comer A, et al. Maryland's Helicopter Emergency Medical Services Experience From 2001 to 2011: System Improvements and Patients' Outcomes. Ann Emerg Med. 2016; 67(3): 332-340.e3, doi: 10.1016/j.annemergmed.2015.07.503, indexed in Pubmed: 26433494. 